\title{
Towards a Framework for Educational University-Industry Cooperation: In- dustry Perspective
}

\section{Prof. Victor Taratukhin, Stanford University}

Victor Taratukhin received his Ph.D. in Engineering Design in 1998 and Ph.D. in Computing Sciences and Engineering in 2002. Victor was a Lecturer in Decision Engineering and Module Leader (IT for Product Realization) at Cranfield University, UK (2001-2004), SAP University Alliances Program Director (20042012). He is Managing Director, Competence Center ERP at European Research Center for Information Systems (ERCIS), University of Muenster, Germany (2012-present) and Visiting Professor at Stanford Center for Design Research (CDR).

Currently teaching at Stanford

ME 310I: The Essential Elements of New Product Development: Business and Industry Perspectives

Dr. Yury V. Kupriyanov, National Research University Higher School of Economics

Deputy professor at Department of Business and Management, School of Business Informatics in National Research University Higher School of Economics, Russia, Moscow

Country Manager for Russia/CIS region of global academic prorgam SAP University Alliances

Dr. Jörg Becker

Prof. Dr. Dr. h.c. Dr. h.c. Jörg Becker, University of Muenster 


\title{
Towards a Framework for Educational University-Industry Cooperation: Industry Perspective
}

\author{
Prof. Dr. Dr. h.c. Dr. h.c. Jörg Becker, University of Muenster, becker@ercis.uni- \\ muenster.de \\ Dr. Dr. Victor Taratukhin, University of Muenster, Stanford University, \\ vtara@stanford.edu \\ Dr. Yury Kupriyanov, National Research University Higher School of Economics, SAP \\ SE, yury.kupriyanov@sap.com
}

\begin{abstract}
Information systems discipline is a quickly developing field of knowledge and to cope with these changes universities have to constantly adjust their curriculum according to industry needs. Therefore universities can highly profit from the cooperation with enterprise partners. On the other hand, enterprises are also interested in closer contact with academia where they can find innovative and commercializable ideas and hire recent college graduates. However, studies still show the discrepancy in needed skill perception between industry and education. Literature on the topic also reports about a number of existing barriers towards establishing successful university-industry cooperation. In this paper, we try to address these problems by proposing a framework for establishing and managing the long-term educational universityindustry cooperation. The framework was constructed based on the results of a case study of an existing cooperation between an IT service company and a regional university. The framework incorporates the industry perspective on the cooperation process.
\end{abstract}

\section{Keywords}

University-Industry Cooperation, Educational Cooperation, Framework, IS education

\section{INTRODUCTION}

Information systems (IS) is a quickly developing discipline, in which to cope with rapid changes in skills demand from the practitioner's side universities have to continuously adjust their curriculum (Lee and Fang 2008). Often higher educational institutions seek for closer cooperation with the industry in order to provide better experience for the students and initiate innovative research projects.

On the other hand IT companies are interested in better relations with academia for hiring talented students and finding commercializable ideas (Cerych and Frost-Smith 1985; Hawking and McCarthy 2000; Thune 2011). In developing countries such as Russia, Taiwan, India or China IT companies have to rely on recent graduates when hiring new employees, as the IS educational programs have been established recently and the job market is not yet filled with experienced specialists. However studies show that in these countries the discrepancy between industry needs and recent graduates skills is rather high (Yen et al. 2003). Therefore big IT companies, which open new departments in developing countries, especially in non-central regions, find it reasonable to intervene in the educational process at the early stages in order to obtain better job candidates in future.

Cooperation between university and industry is not a new idea. Already in the middle of 1980 an overview of university-industry cooperation was published by Cerych and Frost-Smith 
(1985). Nowadays all the big IT companies, such as SAP, Intel or Microsoft conduct summer schools, provide internship positions, organize conferences and exhibitions for (undergraduate students. An example of a successful cooperation might be the SAP university alliance program, internship and graduate fellowship programs from Intel or scholarships from Microsoft Corporation.

However, universities and industry - during their cooperation - face a number of problems mostly caused by the difference in culture and needs of both parties (Cerych and Frost-Smith 1985; Swain 2009). Different studies tried to address the problem by researching success factors (Bruneel et al. 2010; Swain 2009; Thune 2011), intentions for interaction and ways of establishing a cooperation. However little was done in describing the process carrying out the whole cycle of collaboration activities (Thune 2011).

In this paper we try to close the research gap and investigate the process of educational university-industry cooperation in the area of IS from the industry perspective on the example of the Russian market. We have conducted a case study research to get a deeper understanding of the collaboration process between a subsidiary of an international IT service company and a local regional university in Russia. Based on the results of the case study we develop a generalized framework of educational academia-industry cooperation, which can be used by any big or medium sized IT company to improve the hiring of recent graduates by participating in their education at early stages. The framework is mostly based on the industry perspective, which means that the cooperation initiative comes from the industrial partner, which then has to compete for a better standing at the university. The framework also takes into account the university goals and strategy as well as administrative restrictions; however in this paper we have not reviewed these aspects at a fine granular level.

The paper is structured as follows: in the second part of the paper, we present the literature review on university-industry cooperation, applicable success factors and potential problems. We continue with the research design section where we describe the case study setup. In the fourth section, we present the key findings of the case study and develop the educational university-industry collaboration framework, which is presented in the fifth section. We conclude the paper with a discussion and outline the future research steps. 


\section{LITERATURE REVIEW}

Collaboration between universities and enterprise is a complex concept. There exists no single definition of it in the literature. Collaboration may occur in different forms and context (e.g. research, knowledge transfer, lifelong learning, commercialization activities or education), and may have different goals and stakeholders (Anderson 2001; Thune 2011). Swain (2009) has divided the collaboration in a research-oriented and an education-oriented one. Whereas the first type is brightly presented in literature (Anderson 2001; Lee and Fang 2008; Philbin 2008, 2010) including studies on research partnership formation, knowledge transfer or commercializing research results, the educational collaboration is much less frequently addressed (Thune 2011).

In this paper, we concentrate mostly on the educational aspect of the university-industry collaboration. This area is of utmost importance for the IS field where the course curriculum has to be updated constantly in order to provide students with up-to-date technology knowledge and make them competitive on the job market. Knowledge of current trends in IS practice might not be enough, universities should think strategically - which knowledge will be demanded in the next 3-5 years when the graduate students enter the market. Therefore, direct skill requirements from industrial partners might facilitate the problem solution.

According to its focus, educational collaboration can be classified in three groups (Thune 2011):

- development of new educational programs,

- industry invocation in teaching and learning process by thesis supervision, lecturing or conducting research projects,

- transfer between studies and work life (internships, career fairs, trainee or other recruitment programs).

While the last group of activities is relatively easy to realize in short-term, the first two types of cooperation might cause certain difficulties. The problems mostly occur because of the differences in nature and culture of the academia and industry worlds (Bruneel et al. 2010; Cerych and Frost-Smith 1985; Philbin 2010; Swain 2009). The development and introduction of a new educational program is a long-term process, but the industry partner might want to realize it as fast as possible. Universities often lack flexibility in the structure with little communication between different departments, have cumbersome legislative and administrative machinery, certain restrictions and norms which are not always understood by industrial organizations (Cerych and Frost-Smith 1985). When initiating a collaboration industry partners should always keep in mind that universities' mission and main goal is about education and knowledge generation, and not profit or competitive advantage gained by "hiding" the knowledge from their competitors (Bruneel et al. 2010; Swain 2009).

A number of studies were conducted to identify success factors in university-industry collaboration. The study of Thune (2007) shows that previously established ties are a prerequisite to successful collaborative relationships. He further claims that conducting successful collaborations between newly connected partners is difficult due to absence of common understanding, trust and familiarity, which all together form the social capital. The importance of social capital for strategic alliances was also underlined by (Koka and Prescott 2002; Mora-Valentin et al. 2004). Also Bruneel et al. (2010) show that the presence of prior experience and greater level of trust lowers the barriers between university and industry partners. Thune (2011) found out that a successful partnership normally develops in a 
cumulative manner starting with small risk-free projects; therefore both parties should be ready for a slowly developing relationship and be oriented for long-term rather than short-term goals. Bruneel et al. (2010) claim that complicated administrative processes in the universities often increase the transaction-related barriers, and therefore the academia should think about finding straightforward and simple mechanism to establish the interaction. However Thune (2011) has conducted a case study which shows that normally as soon as the formal documents are signed between the parties they choose to communicate informally. Other factors such as geographical proximity of partners are questionable (Mora-Valentin et al. 2004; Thune 2011). Geographical proximity might play a secondary or no role at all for the research collaboration, but be important for the educational one.

Not only the organizational aspect of a university educational collaboration with industry partners should be taken into account, but also the impact of collaboration on the university students, who are the main stakeholders in these joint initiatives. Students and researchers alike both learn in the context of such cooperation. This holds true for a research-oriented as well as education-oriented collaborations. It should be kept in mind that students often may have a "pre-employment look" (Stephan 2001) on the industry, which means that they get to know about the working environment in industry, salaries or the industry research publication process (Stephan 2001). The author outlines the chance for peer learning, through communication with other students (peers), as another possible way of making students profit from the cooperation. Extra curriculum courses or participating in industry projects make the communication between certain groups of students more intensive, as well as allow bringing together students from different departments. Thus both industry and academia should pay more attention to such kind of projects.

\section{RESEARCH DESIGN/METHODOLOGY}

The literature review highlighted possible problems and success factors of university-industry collaboration, which have to be considered by both parties when establishing such a practice. However, little can be found in the literature regarding the concrete process of managing and implementing the educational university-industry cooperation. To close this gap we have conducted a case study. An international IT consulting company and a regional university in Russia, which have recently established an educational cooperation, were in the focus of the research. We aimed at analysing the current situation and future improvement potentials of this relationship.

The university chosen for the case study is one of Russia's leading regional universities, located not in a central region, with 18 faculties and 18495 students in the academic year 2012/2013. During the case study we have analysed the situation in five of 18 faculties: Applied Mathematics, Informatics and Mechanics, Computer Sciences, Economics, International Relations and Romance and Germanic Philology. These faculties were chosen either due to their research connections to Information Systems or the proficiency of the students. The university is comparable in structure, size and objectives to many other universities in Russian regional cities with population over one million.

The IT service company is a Russian subsidiary of a big European telecommunication and IT service provider. It employs more than 900 consultants, developers, sales people and other functions in 4 offices in different cities in Russia. The services of the company span consulting on SAP solutions integration and customization as well as software development. In the case study we have analysed the situation at the youngest of the four sites, which faced the strongest hiring challenge. Due to cultural reasons good specialists are not ready to move to regional 
cities in Russia, and as a result the company have to target the hiring process on the recent graduates from local universities. The main difficulty lays in the fact that students had a strong background in mathematics, physics and other fundamental sciences, however the level of knowledge of current IT technologies was rather low. As a result the decision was made to set up an initial contact with students at early stages of their studies and start cooperation with the local higher educational institutions.

Currently the company already maintains a business lab in the premises of one of the local universities to train students in five different courses with practical industry applicability. Two programming languages are taught: Java and ABAP. The ABAP (Advanced Business Application Programming) course takes two months and is scheduled twice a year. The course is also targeted on improving the students' abilities to design and develop ERP systems. The second programming course on Java lasts more than 4 months and is also scheduled twice a year. The students learn fundamental software development skills using the Java language. Two further courses are focused on software testing and support (user help desk). With a shorter duration of two months and four weeks correspondingly, these programs aim at developing basic skills to immediately enable students to start working for the company as quality assurance specialists or help desk agents. The longest course in the business lab program is the SAP training program, which lasts eight months covering the whole academic year. The students get deep insights into four main SAP modules and obtain practical experience in using ERP systems. After the successful completion of any course in the business lab program best students are often rewarded with a job position at the company's regional site.

The lecturers at the business lab courses are employees of the university and the IT service company. As all the courses are not included in the standard university program and accept only a limited number of participants, the students have to apply for each program individually and are then chosen according to their skills and grades. The other problem of the courses not being part of the university's curriculum is that they could interfere with course schedules of the student's regular program.

The analysed company was not the only company hosting such a business lab at the university. Due to this competition, the company needs to make sure to promote its offers sufficiently and attract the best students. In addition, with respect to its international profile and in particular due to the company's headquarters location in Germany, a special focus is made on German speaking students, which study at the departments related to languages and international relations. The offers are promoted personally in lectures, on a dedicated website as well as on social media channels.

To get a better understanding of the current situation from the industry as well as academia perspectives we have conducted a series of personal interviews with students and with university and industry representatives. Based on the result of the interviews we have composed and published an online questionnaire for the students.

The face-to-face interviews were semi-structured. In order to get a 360 degree view on the situation we have attracted different groups of interviewees: students who took part in a joint university-industry program, those who never attended the program or quitted the program, the university lecturers and administration staff as well as company representatives. For each group of interview participants we used the same base interview questions. The base interview questions were intended to gather information about the awareness of joint programs, the channels of information and personal experience with the programs. The questionnaires were 
extended with group-specific questions. For example these students who already took part in joint-programs were asked about their experience and the current situation in the programs; students, who did not attend any joint-program, were interviewed about the awareness of such programs and their motivation to participate; university and industry officials were asked about the reasons for university-industry collaborations and the current state of the relationship.

In total we have conducted 40 interviews, 26 of the interviewees were students, of which 13 got a position at the company after attending a joint-program. Among the 14 non-student interviewees 5 were representatives from the industry side and 9 were university staff members. All the interviews were recorded, transcribed and then analysed.

During the second phase of the case study we have published an online questionnaire among students to get more insights about the awareness of joint-programs, to assess existing skill sets and work preferences and to investigate demands for university-industry collaborations. The questions were available in both - English and Russian - languages to avoid misunderstandings due to insufficient English language proficiency. The questionnaire was distributed through social network web sites and as a result we have got 58 responses from the students.

The skill-related questions combined language and IT skills like the office suite, programming languages and SAP. We further asked the students for their preferred future work environment, job profiles and country preferences. The last part of the online interview dealt with universityindustry collaboration. The main goal was to find out what kind of collaboration, e.g. summer schools, research projects or international exchanges, and type of extra curriculum courses, is mostly demanded by students.

With our research we targeted on gaining more insight in the motivation and experience of both sides of the interaction - industry and university. We further aimed to derive general problems arising within the current setup of the collaboration between the IT service company and the higher educational institution. Based on the results of the analysis presented in the next section, we a framework for university-industry collaboration where we consider short- and long-term activities, which have to be undertaken in order to build a successful relationship. The framework is industry-oriented, which means that we review the situation where the industry partner acts as an initiator of the collaboration and has then to compete for a better representation in the university.

\section{KEY FINDINGS}

During the interview with bachelor and master students, it was found out that in general students have a high motivation to participate in the joint-program. The company has a strong, positive image of an international company with interesting and innovative IT projects. A strong desire to start the carrier at this particular company was expressed regularly by the students during the face-to-face interviews. Many students brought this up as the main reason to choose the program of this particular IT company and not a program from a competing local organization.

Among the incentives to participate in the business lab program students mentioned the practical application of theoretical university contents, better career chances and a possibility of improving their language skills. $60 \%$ of students answered that they are interested in the opportunity to "combine theory and practice". $40 \%$ of them saw the "possibility for further employment" as the main motivation factor. 
The students' motivation for future career opportunities seems to overcast the choice for a particular course. Despite the fact that less than a half of the students prefer "testing and quality assurance of ERP systems" as a future job position, the course for software testing still receives more applications than the company can accept for this course. As students see the business lab as a first step towards a regular job, they tend to choose short-duration courses in order to get into the company as fast as possible hoping that they can then change the carrier direction. Opposite to that the company would prefer to get the right students in the right courses and does not want to teach the somebody, who wants to be an SAP consultant in future, software testing technologies.

The students as well as university and industry representatives state that the joint educational program shows high practical applicability, as it was specifically designed to teach new IT technologies. The interviewees also mentioned that in comparison to the joint-program structure, the university curriculum is out-dated and no longer meets the fast changing requirements of the IS field. The joint program is strongly seen as an opportunity to close this gap.

During the interviews we have also analysed the satisfaction level of the students who participate in the courses. Over sixty precents of the students are satisfied with the performance of the lecturers. The lecturers are able to react to student's needs and fulfil their expectations for practical relevance of the course content. The practical relevance is mostly achieved by the fact that most of the lecturers are industry experts.

On the other hand a number of negative aspects of the collaboration were discovered during the student interviews.

First of all the content of the program and the program itself are not well presented to the potential participants. The students often are not able to get important content and organizational course information, which lead to frustration and cancellation of the courses. We have then analysed the program web site and found out that the information about the courses, such as course content, course schedule or initial knowledge requirements for course participation, was not sufficiently presented, was out-dated, incorrect or misleading. Some of the interviewees admitted that this misleading information was the reason for quitting the course.

The workload was one of the factors, which influenced the negative experience from the courses. As all of the students had to combine the business lab program with their regular studies they have suggested to reduce the workload in terms of time and/or contents. Moreover because of this reason the program was often seen by professors as interfering the general studies and not always recommended for participation. The students themselves complained of too high workload and sometimes of impossibility to combine both university and jointprogram courses.

The interviews with industry representatives revealed that the company invested many resources for the official introduction of their business lab. It was important to overcome administrative processes at the university as well as find supporters for the project. In our case the company tried to create a positive awareness by holding a public ceremony with important representatives from academia, industry and politics.

The course structure at the business lab is well aligned with the current service portfolio of the IT company. However the business lab lacks ability to flexibly adapt the courses' content to the fast-changing skill requirements. The case study revealed major technology trends, which 
the company is going to follow in the nearest future. These technologies will require new skill sets of young professionals. As universities are not able to adapt the curriculum in short- and medium-term, the company's business lab must be able to fill this gap, although there currently exists no process for the setup of new courses for the business lab in the company.

\section{UNIVERSITY-INDUSTRY COOPERATION FRAMEWORK}

Based on the case study findings and the success factors identified through literature review we propose a generalized framework for university-industry cooperation in the area of IS, which is depicted in figure 1 . The framework is intended to formalize the steps for a successful longterm relationship with academia initiated by the industry partner. For each step we define the core activities and suggest the criteria to be considered in order to establish a valuable cooperation for the both sides.

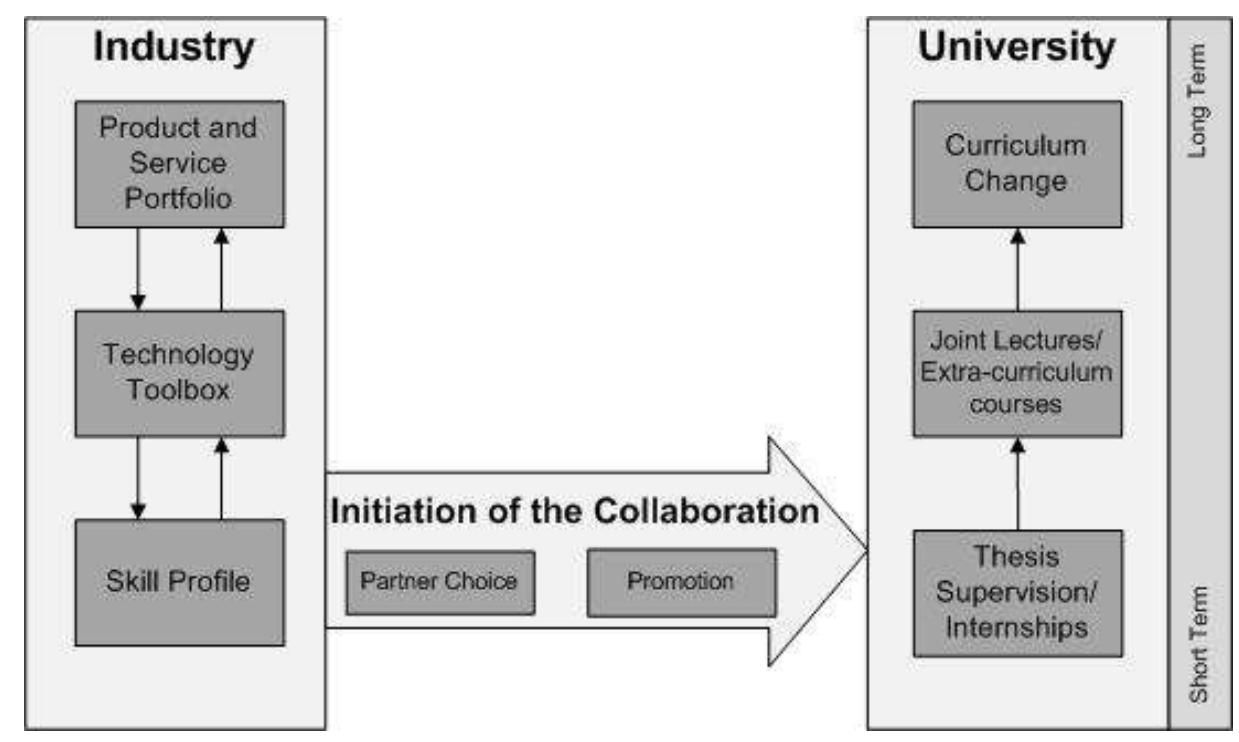

Figure 1 University-Industry Cooperation Framework

The framework consists of two parts, which represent industry and academia perspectives. The process is initiated on the industry side with an internal analysis of the future project portfolio and the corresponding skill demand, which results in subsequent short-, middle and long-term activities conducted with the university partner. The two parts of the framework are connected with a bridge, which depicts the basic steps towards establishing and promoting the collaboration activities at the university.

As we have already mentioned in the introduction the framework is industry-oriented, which means that the whole collaboration process is initiated by the enterprise-partner. At the very first step towards the cooperation the company has to think strategically and define the portfolio of products and services, which possibly will create a demand for new employees with knowledge, which at the moment is not widely present throughout the organization. For example the company may want to join the growing trend in the area of Big Data solutions and extend its portfolio with Big Data products and services for some specific industry in the next 3 years. In this case a number of Big Data solutions for different industries, e.g. healthcare, automotive, oil and gas, are added to the project portfolio profile.

The strategically defined products and services impose certain requirements on technologies. The company should form a technology toolbox, which consists of industry and solutionindependent technologies. These technologies can be flexibly used for the projects defined in the product and service portfolio. Big Data is one example to illustrate this relation. The term 
Big Data includes a number of solutions to store and analyse huge amounts of data. Technologies, such as in-memory or solid-state-disc storages, NoSQL databases or frameworks for distributed data analysis, i.e. Hadoop, are needed to realize these solutions. While Big Data solutions might be adapted to particular customers or industries, the technologies in the toolbox are applicable for each of the planned portfolio projects.

The technology toolbox itself put requirements on employee skills. An assessment of the available employee skills at the company should be conducted in order to define the gap and analyse future requirements for the personnel. Hiring recent graduates, who already have knowledge in the technology, can then close the gap. In order to assure that the students will have the necessary knowledge the company should establish the contact to these students already before their graduation. Thus in case of Big Data solutions in the company's portfolio and graph database technologies in the technology toolbox, the company might realize a need in a group of specialists who possess profound statistical and database management skills with respect to the new developments in this area.

After the skill requirements were defined, the process comes to the bridge where the cooperation is initiated. As a first step the right partner should be chosen. Based on the importance of social capital identified by the literature review and in particular the big role of already established ties, the company should first look for already existing connections. Such connections might come from previously conducted joint-projects or employees' relationships to their former professors. In case there is no previously created connection or in case the connections do not suite the current task the company should look for new ones. In this case such criteria as university profile, rating or location, might be taken into account. In our particular case study the choice for the cooperating university was made mainly due to its location in the same city as the company office. The current situation in the country made it impossible to attract students from central regions, where the universities have higher ratings and better suited profiles. Other regional cities were not considered because of the distance and resulting difficulties in communication. The criteria of university rating and profile were then applied to all local universities in order to choose the best suiting partner.

The second step towards establishing the cooperation is promotion. In order to make the cooperation attractive to students and eliminate possible conflicts with university employees the company should create a positive image from the very beginning. Providing good information about the company at local university events, company web site and social networks will assure a public awareness. In our case study, the company made huge efforts at the very beginning of the collaboration by inviting the representatives from the headquarters to talk about the company and cooperation possibilities with students and university employees.

Taking into account - revealed by the literature review - the fact of university-industry relationship being built slowly, the company should at first consider short-term, low-risk projects and then gradually intensify the relationship to middle- and long-term initiatives. With short-term engagements, we refer to the collaboration initiatives with duration varying from several days to half a year. Examples for short-term collaboration are guest lectures conducted by the industry experts, project seminars with a business partner, internship programs and bachelor/master thesis offerings and co-supervision. Such short-term initiatives play an important role in the development of the university-industry collaboration by initiating the communications and building trust among all stakeholders, including university officials, faculty members, students and industry representatives. The company should not forget about the communication problems between departments in the universities, which mean that running short-term projects at one department might not be enough to build a good image among all the university officials. Our case study has revealed that one of the departments was 
positive about the cooperation, while the professors and lecturers of another one were not satisfied with the cooperation and tried to talk students out of participating in the activities. The reason for it was that all the conducted short-term cooperation activities were concentrated only on one of the university faculties.

Medium-term collaborations range over a longer period with a fixed duration not longer than 3 years. Examples include joint participation in lectures, where an industry representative holds a part of the lecture or even the creation of a so-called business lab, where the company provides own extra curriculum courses to the university students. While short-term collaborations are easy to setup the company should now be aware of possible complex administrative processes found at the university. It might be difficult to establish a business lab officially and to convince important stakeholders to support such a business lab. The lecturing might be also problematic, as sometimes due to the internal university regulations the university should officially employ the lecturers.

Long-term collaborations take years to establish. The collaboration between university and industry should already be proofed valuable at this point of time. Long-term collaboration is the type of collaboration, which the company should tend for, as the company becomes a trustful partner consulting the university with an industry perspective on education. In the longterm the adaptation of the curriculum can be undertaken which will complement current business lab courses or even replace them. The university together with the company might decide that certain skills and technologies taught in the business lab or used in project seminars are not just a "current trend", but also a topic, which the students should have as a fundamental knowledge. Thus a certain course can evolve from the business lab and - with necessary adjustments to university guidelines - become a part of the university curriculum. The university profits from the updates to the program and the company can now concentrate on recently appeared technologies.

\section{CONCLUSION}

Educational university-industry cooperation is an important activity in the field of IS. On the one hand universities want to keep their curriculum up-to-date and relevant for the practice. On the other hand industry is interested in having well trained recent graduates as new employees. Educational cooperation with academia gives IT companies a chance to get in contact with future employees already at early stages of their education by providing internship positions or supervising their bachelor or master thesis. In the long term the company has a chance to influence the university curriculum, in order to assure that the students get up-to date technology knowledge before they start their job.

Although the topic of university-industry collaboration is brightly discussed in the literature, there is little done in the area of educational cooperation. Most of the literature is concentrated on the topics of cooperating partner characteristics and the incentives for cooperation. However the topic of the process for cooperation is underrepresented in the research at the moment.

In this paper we have introduced a framework for educational university-industry cooperation. The framework was constructed based on the results of the case study about the cooperation between a department of an international IT service company in a regional city in the Russian Federation and a local university. We have analysed already established cooperation activities between the two parties and conducted interviews with students, the company and university representatives. The analysis of the interviews has shown that although the cooperation seems to function good at the moment there are certain problems, which have to be solved if the company wants to continue and improve their cooperation activities. 
The framework describes the main steps towards a stable and successful long-term universityindustry cooperation. The framework is industry oriented, thus the process is initiated at the enterprise partner side. The activities within the framework are divided between the preparation activities conducted solely by the company and collaboration activities conducted by both parties. Collaboration activities in their turn are separated in three groups according to the time needed for realization. We have also defined success factors, which have to be considered by the industry partner when performing each of the steps.

The framework has not been evaluated yet, but the company, analysed during the case study, is going to consider the proposed solution in future. According to the results of the framework application, it might be adjusted to better fit the industry requirements and specific academia restrictions. We ague that our framework is general enough to be used by any big- or mediumsized company working in the field of IS, which has a demand in graduate students with relevant and up-to-date technology knowledge. The limitation of the framework is in it's exclusively industry orientation. The framework is also targeted only on educational aspects of cooperation. Among the potential future improvements the case of research cooperation can be reviewed, as well as the possibility of initiating cooperation from the university side can be added.

\section{REFERENCES}

Anderson, M. S. 2001. "The complex relations between the academy and industry: Views from the literature," Journal of Higher Education (72:2), pp. 226-246.

Bruneel, J., D'Este, P., and Salter, A. 2010. "Investigating the factors that diminish the barriers to universityindustry collaboration," Research Policy (39:7), pp. 858-868.

Cerych, L., and Frost-Smith, B. 1985. "Collaboration between higher education and industry: an overview," European Journal of Education (20:1)Wiley, pp. 7-18.

Hawking, P., and McCarthy, B. 2000. "Industry collaboration: a practical approach for ERP education," in Proceedings of the Australasian conference on Computing education, Ainslie E. Ellis (ed.), Melbourne, Victoria, Australia, pp. 129-133.

Koka, B. R., and Prescott, J. E. 2002. "Strategic alliances as social capital: a multidimensional view," Strategic Management Journal (23:9), pp. 795-816.

Lee, S., and Fang, X. 2008. "Perception Gaps about Skills Requirement for Entry-Level IS Professionals between Recruiters and Students," Information Resources Management Journal (21:3), pp. 39-63.

Mora-Valentin, E. M., Montoro-Sanchez, A., and Guerras-Martin, L. a. 2004. "Determining factors in the success of R\&D cooperative agreements between firms and research organizations," Research Policy (33:1), pp. $17-40$.

Philbin, S. 2008. "Process model for university-industry research collaboration," European Journal of Innovation Management (11:4), pp. 488-521.

Philbin, S. 2010. "Developing and Managing University-Industry Research Collaborations through a Process Methodology/Industrial Sector Approach.," Journal of Research Administration (41:3), pp. 51-68.

Stephan, P. E. 2001. "Educational implications of university-industry technology transfer," The Journal of Technology Transfer (26:3), pp. 199-205.

Swain, C. 2009. "Improving academic-industry collaboration for game research and education," in Proceedings of the 4th international conference on Foundations of Digital Games, New York, USA, pp. 191-198. 
Thune, T. 2007. "University-industry collaboration: the network embeddedness approach," Science and Public Policy (34:3), pp. 158-168.

Thune, T. 2011. "Success Factors in Higher Education-Industry Collaboration: A case study of collaboration in the engineering field," Tertiary Education and Management (17:1), pp. 31-50.

Yen, D. C., Chen, H.-G., Lee, S., and Koh, S. 2003. "Differences in perception of IS knowledge and skills between academia and industry: findings from Taiwan," International Journal of Information Management (23:6), pp. 507-522. 